\title{
Major medical conditions and VA healthcare costs near end of life for veterans with spinal cord injuries and disorders
}

\author{
Wei Yu, PhD; ${ }^{1 *}$ Bridget Smith, PhD; ${ }^{2-3}$ Shirley Kim, MPH; ${ }^{1}$ Adam Chow, BA; ${ }^{1}$ Frances M. Weaver, PhD $^{2,4}$ \\ ${ }^{1}$ Health Economics Resource Center, Department of Veterans Affairs (VA) Palo Alto Health Care System, Palo Alto, \\ CA; ${ }^{2}$ Center for Management of Complex Chronic Care, Spinal Cord Injury Quality Enhancement Research Initiative, \\ Edward Hines Jr VA Hospital, Chicago, IL; ${ }^{3}$ Institute for Healthcare Studies and ${ }^{4}$ Department of Neurology, \\ Northwestern University, Chicago, IL
}

\begin{abstract}
We analyzed healthcare costs and medical conditions for 2,008 veterans with spinal cord injuries and disorders (SCI/Ds) near end of life. The average age at SCI/D onset and/ or occurrence was 42 years and at death was 66 years. The conditions that incurred the most costs included cancer (20.9\%), influenza and/or pneumonia (15.1\%), heart disease (13.5\%), septicemia (5.9\%), diabetes (5.3\%), and stroke (5.1\%). The average cost was $\$ 24,900$ in the second year before end of life and reached $\$ 61,900$ in the final year. Before end of life, costs accelerated during the final year from $\$ 3,100$ in month 12 to $\$ 14,600$ in the final month.
\end{abstract}

Key words: cancer, cause of death, costs, economics, end of life, pneumonia, spinal cord diseases, spinal cord injury, veterans, veterans hospital.

\section{INTRODUCTION}

The United States has over 200,000 persons with traumatic spinal cord injuries (SCIs), and roughly 10,000 new cases are added each year [1-3]. Estimates of total annual costs of caring for patients with SCI in the United States have ranged from $\$ 7.74$ to $\$ 9.45$ billion (1995) [45]. The estimated costs (2006 dollars) during the first year following injury ranged from $\$ 741,425$ a person with high tetraplegia to $\$ 218,504$ for an incomplete injury at any level, and a person's lifetime costs ranged from $\$ 2.9$ million for a high-level injury (e.g., a person injured at the age of 25) to $\$ 472,392$ for an incomplete injury occurring at the age of 50 [6].
Limited research exists that examines the epidemiology and costs of nontraumatic spinal cord disorders. Frequent causes of spinal cord disorders include tumors, spinal stenosis, infections, ischemia, congenital disease, and myelitis [7]. Estimates of incidence of spinal cord disorders vary depending on the setting; approximately 29 percent of SCI admissions in a regional Model Systems program were nontraumatic [7]. Other studies have reported similar numbers [8-9]. For patients $>40$ years of age, however, Murray and Kusier found that 87 percent of patients had nontraumatic injuries [9]. Persons with nontraumatic injuries are reported to be older and more likely to be married than those with traumatic injuries [7].

The Department of Veterans Affairs (VA) cares for veterans with traumatic SCIs and for veterans with spinal cord disorders. They account for 22 percent of all individuals

\footnotetext{
Abbreviations: ACF $=$ Average Cost File, BIRLS $=$ Beneficiary Identification and Records Locator Subsystem, DOB = date of birth, FY = fiscal year, GLM = generalized linear model, IRB = institutional review board, NPCD $=$ National Patient Care Database, $\mathrm{SCD}=$ Spinal Cord Dysfunction, SCI = spinal cord injury, SCI $/ \mathrm{D}=$ SCI and disorder, QUERI = Quality Enhancement Research Initiative, VA = Department of Veterans Affairs.

*Address all correspondence to Wei Yu, PhD; School of Public Economics and Administration, Shanghai University of Finance and Economics, 777 Guoding Rd, Shanghai, China 200433; 86-21-6590-4799; fax: 86-21-6510-4264.

Email: wyu2@stanford.edu

DOI: 10.1682/JRRD.2006.08.0102
} 
with SCI and disorders (SCI/Ds) in the United States [2]. Persons with SCI/D often experience impaired function and secondary complications resulting from their condition and need life-long interdisciplinary healthcare. Consequently, persons with SCI/D use substantial healthcare resources. Medical care for persons with SCI/D during their end of life is likely to be more intensive than for other patients. Similar to the general population, persons with SCI/D develop chronic illnesses as they age. However, because of the nature of their injury or impairment, they often experience these chronic illnesses at a younger age and/or have additional complications related to these medical conditions [10-11]. To our knowledge, limited literature is available about major medical conditions and costs near end of life for persons with SCI/D. In this article, we examined medical care costs and major conditions near end of life among veterans with SCI/D receiving care from the VA.

\section{METHODS}

We identified veterans with SCI/D who used the VA healthcare system during their final 24 months of life and died between October 1, 1999, and September 30, 2001 (fiscal years [FYs] 2000 and 2001). Following the definition developed by the VA SCI Quality Enhancement Research Initiative (QUERI), we classified veterans as SCI/D if the first four digits of their International Classification of Diseases-9 codes included 8060-8069, 95209524, 9528, 9529, 3441, 9072, or 3440 in their inpatient or outpatient records. After excluding 42 veterans (2\%) who had utilization records that dated after their dates of death, we found that the final study cohort included 2,008 veterans with SCI/D who died in FY2000 or FY2001.

We used several VA data sets for this study: VA Beneficiary Identification and Records Locator Subsystem (BIRLS), VA National Patient Care Databases (NPCDs), VA Health Economics Resource Center Average Cost File (ACF), and the VA Spinal Cord Dysfunction (SCD) registry. Files from FY1998 through FY2001 were compiled to create 24 months (final 2 years) of data for each veteran in the study cohort. The BIRLS file contains information on veterans who obtain any benefits from VA and includes date of death, date of birth (DOB), and sex. The NPCD contains data on inpatient and outpatient care, including diagnoses, dates of services, and demographic information. The ACF contains cost data for inpatient and outpatient care at VA facilities. The VA SCD regis- try includes information about characteristics of veterans with SCI/D, including the level and etiology of injury.

\section{Cost Estimation}

For VA inpatient medical or surgical care, costs were allocated based on relative weights derived from a regression generalized linear model (GLM) using veterans' demographic information and Medicare's Diagnosis Related Group, length of stay, and use of intensive care unit [12]. For other inpatient care that includes long-term hospital care and VA nursing home care, we estimated costs based on national per diem costs [13]. For outpatient care, which includes VA home care, we estimated costs using relative weights of common procedures specified by the common procedure terminology codes [14]. Because ACF does not include outpatient pharmacy data, these costs were not reported in our findings. Furthermore, we were unable to include costs related to attendant or long-term care received outside the VA. For this article, healthcare use and costs for veterans with SCI/D in the final 24 months of life are limited to VA use and costs only.

\section{Spinal Cord Injury Status}

SCI/D status was classified by whether paralysis was a result of injury (traumatic) or disease process. Level of injury or impairment was defined as paraplegia or tetraplegia. Because 827 (41\%) of subjects did not have data in the VA SCD registry, we grouped those veterans together as having a missing status for level of injury.

\section{Demographics}

Subjects were divided into four age groups: $<65,65$ to 74,75 to 84 , and $\geq 85$ years old. Race was categorized as black, white, or other. Hispanic black and Hispanic white were included in the black and white groups, respectively. DOBs and race were obtained from BIRLS and NPCD files. When data differed, we used the BIRLS data.

\section{Major Medical Conditions}

Persons with SCI/D often had medical conditions that required significant treatment near end of life. We defined a condition that accounted for most of the cost incurred in the final year as the "major medical condition near end of life." We grouped principal diagnoses of inpatient or outpatient care into major categories using the classification of vital statistics for cause of death [15]. Costs in the final year were calculated for each diagnostic category, and the most costly diagnostic category was identified for each 
veteran as the major medical condition near end of life. We reported the top 10 most common major medical conditions occurring near end of life.

This study was reviewed by the human studies institutional review boards (IRBs) of the respective institutions of the authors. Because this was a retrospective study, the IRBs considered this work to be exempt from periodic review.

\section{Analyses}

We estimated healthcare costs by age, race, sex, injury status, and major conditions near end of life. We also investigated costs at 30-day intervals during the final 24 months of life. For inpatient stays that crossed two or more 30-day intervals, we proportionally allocated costs of an inpatient stay to each 30-day interval according to the length of stay in each interval. Because VA SCI centers provide both acute and nonacute care in SCI bed sections, we were unable to identify specific types of inpatient care for those who were admitted into an SCI bed. Therefore, we combined all inpatient costs into a single category.

To examine cost distribution, we calculated the total inpatient cost for each of the final 24 months of life. Because total cost was entirely dominated by inpatient cost, we did not calculate the distribution of total cost for each month.

To understand the marginal impact of age, sex, race, major medical condition, and injury status on cost, we conducted a multivariate regression analyses using GLM [16]. GLM is commonly used to fit skewed data, such as healthcare costs [17-18]. We analyzed cost impacts of these variables in five periods: the final 30 days, 90 days, and 180 days of life; the final year of life (year 1); and the second year before end of life (year 2).

\section{RESULTS}

\section{Descriptive Statistics}

Table 1 describes demographics, injury status, and major medical conditions of the study cohort with their associated costs. The average age at time of injury onset was 42 years and at death was 66 years. For veterans with traumatic injuries, the average age at time of injury onset was 40 years and the average age at death was 65 years. Veterans with nontraumatic injuries were significantly $(p<0.001)$ older at the time of injury onset (55 years) and at death (69 years) than veterans with traumatic inju- ries. The majority of veterans were male (98.6\%). Among those with data indicating etiology and level of injury, 68 percent had traumatic injuries and 53 percent had paraplegic-level injuries. Half the subjects had cancer, influenza and/or pneumonia, or heart disease as a major medical condition. Septicemia, stroke, chronic obstructive pulmonary disease, diabetes, nephritis, hernia, and other blood vessel disorders were the next common set of major medical conditions, accounting for 29 percent of the total. Overall, nearly 80 percent of the subjects had one of these top 10 major medical conditions near their end of life.

Excluding costs for prescription drugs, veterans with SCI/D incurred an average of $\$ 61,900$ in VA-related healthcare costs in year 1 and $\$ 24,900$ in year 2 before end of life. Inpatient care accounted for 93 percent of the total in year 1 and 86 percent in year 2. Costs declined with increasing age in both years except for the $\geq 85$ group in year 1; blacks incurred 14 percent more costs than whites in year 1 and 24 percent more in year 2. For injury status, costs were similar for those with traumatic injuries and spinal cord disorders; veterans with paraplegia had the same average cost as those with tetraplegia in year 2, but 6 percent had greater costs in year 1 . Veterans who had missing level of injury data had 22 percent less costs than those with injury information in year 1 and 42 percent less in year 2.

Of the 10 most common major medical conditions, the group of veterans with SCI/D who had nephritis incurred the highest costs $(\$ 83,000$ in year 1 and $\$ 37,000$ in year 2) near end of life. Veterans with SCI/D who had cancer, heart disease, septicemia, stroke, or hernia incurred lower costs than the average $(<\$ 60,000)$ in year 1 . Conversely, those who had a major medical condition other than the top 10 conditions just described incurred average costs of $\$ 69,000$ in year 1 and $\$ 28,000$ in year 2, which were higher than the average cost of all decedents.

Figure 1 shows the cost trends during the final 24 months of life. Average cost was relatively stable at approximately $\$ 2,000$ over the total of year 2 and started increasing during year 1 . Costs increased rapidly from the month 8 before end of life and reached a peak in the final month of life. The share of inpatient costs increased consistently over time from 85 percent in month 24 before end of life to 98 percent in the final month.

Figure 2 shows distributions of inpatient costs during the final 24 months of life. Figure 2 clearly shows that healthcare costs near end of life are dominated by inpatient care costs. Even so, three-fourths of our study 
Table 1.

Healthcare costs in final year of life (year 1 ) and second year before end of life (year 2) (final 24 months) for veterans $(N=2,008)$ with spinal cord injuries and disorders — by demographics, injury status, and major conditions (dollars in thousands [k]).

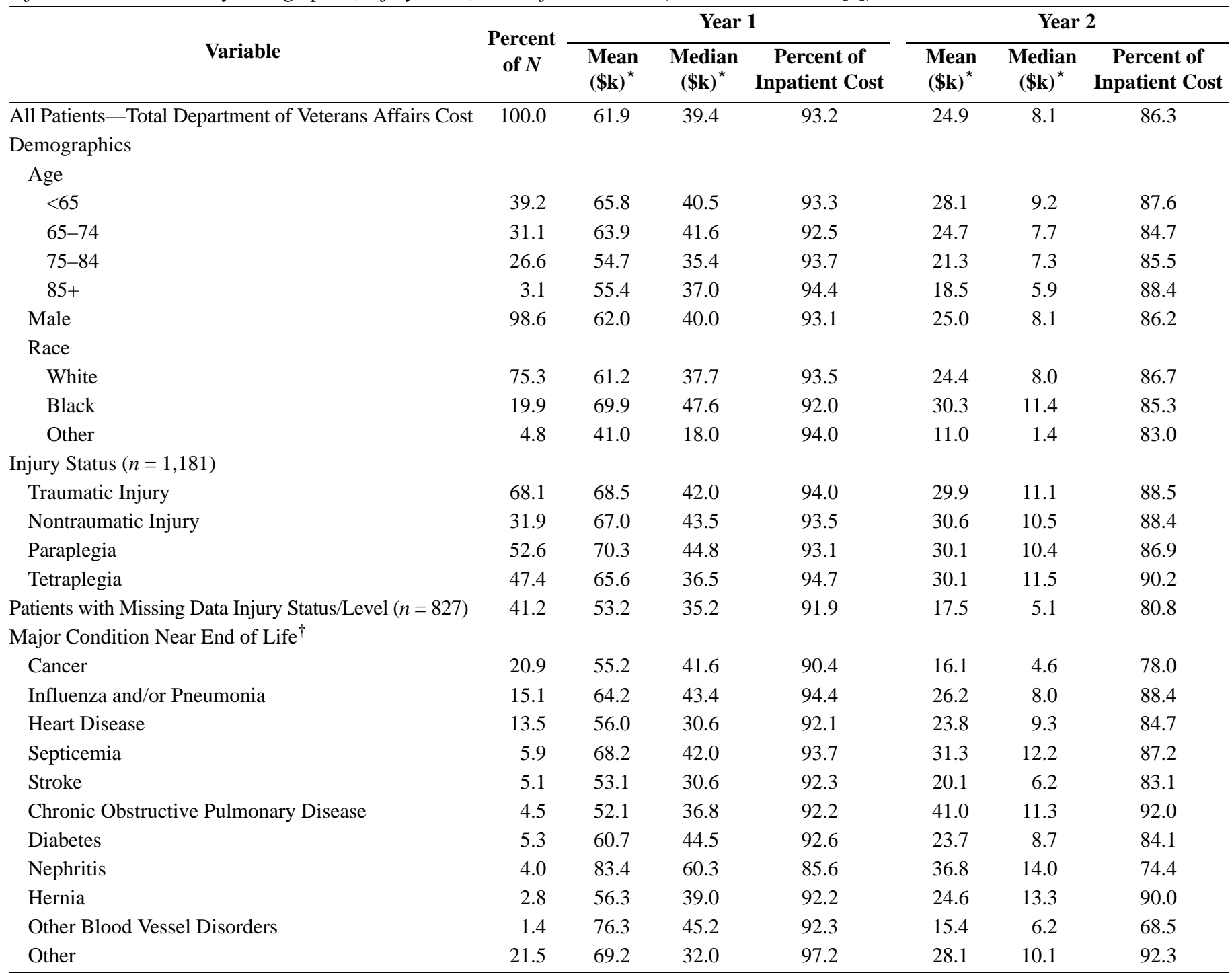

${ }^{*}$ Rounded to nearest $\$ 100$ (in thousands of dollars), excludes pharmacy costs.

${ }^{\dagger}$ Major condition was based on costs in year 1 .

sample did not have any inpatient costs until month 7 from end of life and half did not incur inpatient costs until the final month.

\section{Multivariate Regression Analyses}

Table 2 presents the regression coefficients of the cost models in five different time periods. These coefficients reflect the marginal effects of demographics, injury status, and major medical conditions on costs at different times as patients approached death. The joint tests in the regression analyses show that age had no impact on cost in the final 30-day, 90-day, and year-2 periods. However, a significant difference can be seen between the 75 to 84 and $<65$ age groups in the final 180-day and year-1 model. Costs for the "other" race group were significantly lower than the white group for all five time periods. Among those with injury information, no differences in costs were found between veterans who had traumatic injuries and spinal cord disorders or by level of injury. Veterans treated in an SCI center incurred more costs 


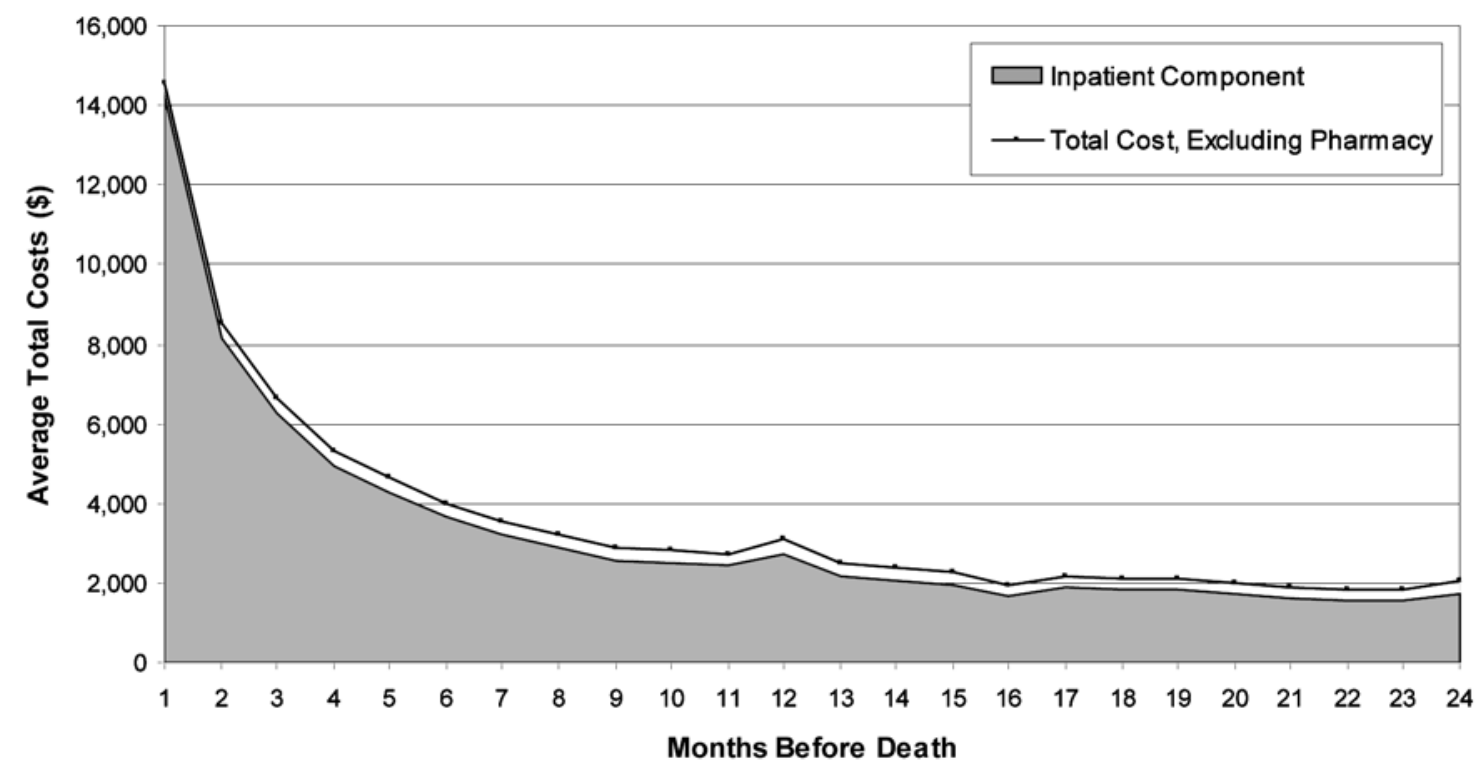

Figure 1.

Average total monthly costs during final 24 months of life for veterans with spinal cord injuries and disorders $(N=2,008)$.

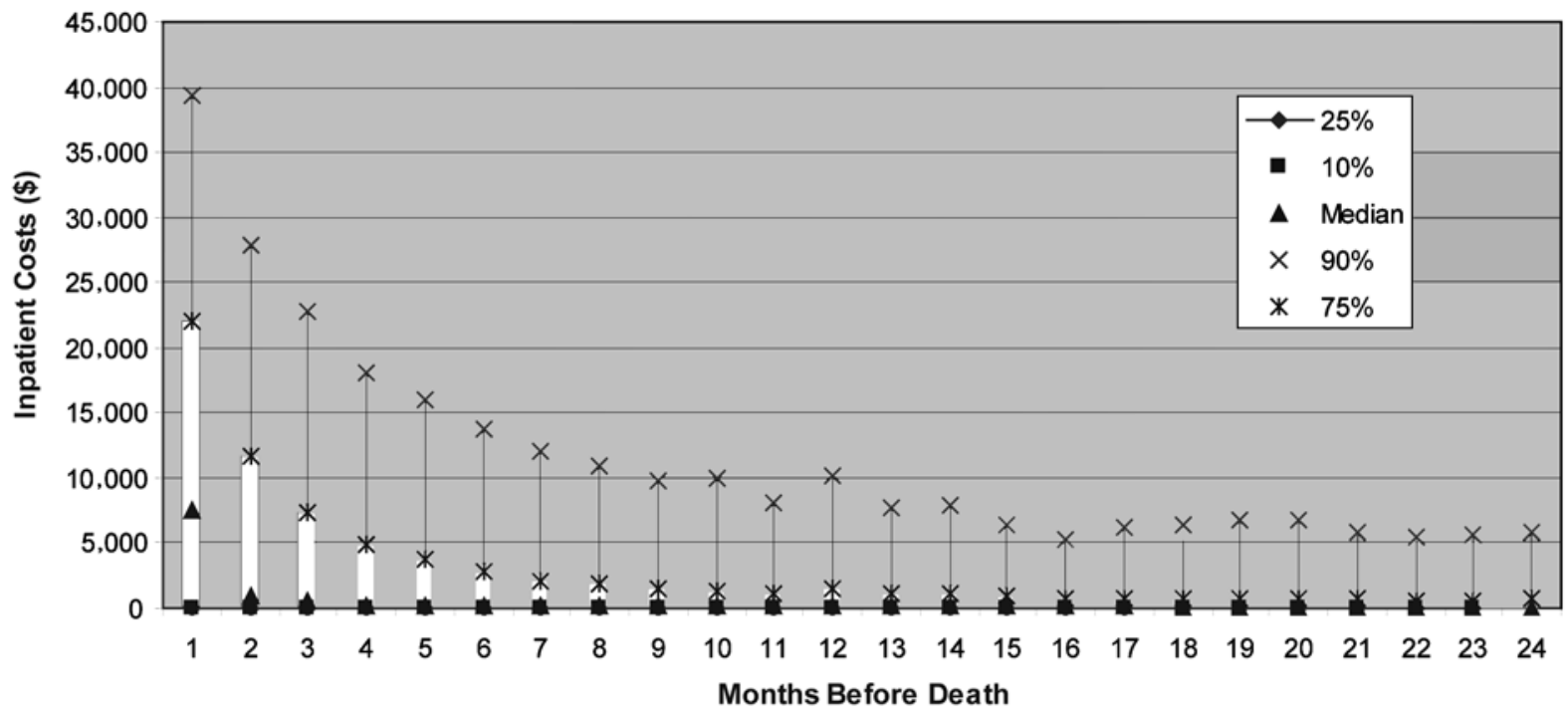

Figure 2.

Distribution of total inpatient costs during final 24 months of life for veterans with spinal cord injuries and disorders $(N=2,008)$.

than those treated in a VA facility without a specialized SCI center during the final 90 and 180 days and year 1. Although none of the top 10 major medical conditions was significantly different from the group of all other conditions, the joint test showed that they were significant for all five time-period models.

\section{DISCUSSION}

This study documented VA healthcare costs and major medical conditions of veterans with SCI/D who received care from VA during their final 24 months of life. It yielded four important findings: First, veterans with SCI/D received 
Table 2.

Regression coefficients of multivariate cost analyses using generalized linear model (GLM) for veterans $(N=2,008)$ with spinal cord injuries (SCIs) and disorders near end of life.

\begin{tabular}{|c|c|c|c|c|c|}
\hline \multirow{2}{*}{ Independent Variable } & \multicolumn{5}{|c|}{ Dependent Variable: Total Cost } \\
\hline & Final 30 Days ${ }^{*}$ & Final 90 Days* & Final 180 Days $^{\dagger}$ & Year $\mathbf{1}^{\dagger}$ & Year $2^{\dagger}$ \\
\hline \multicolumn{6}{|l|}{ Age (years) } \\
\hline $65-74$ & 5.06 & 2.40 & -0.15 & -4.03 & -3.64 \\
\hline $85+$ & 7.37 & -9.74 & -14.64 & -18.28 & -16.05 \\
\hline \multicolumn{6}{|l|}{ Race } \\
\hline Black & 8.28 & 7.04 & 8.90 & 14.02 & 13.40 \\
\hline \multicolumn{6}{|l|}{ Injury Status } \\
\hline Nonmissing Injury Status & -4.38 & -0.03 & 9.38 & 21.39 & $26.54^{\S}$ \\
\hline Nonmissing Nontraumatic & -1.65 & -1.89 & -6.31 & -3.38 & -1.23 \\
\hline Nonmissing Tetraplegia & -1.29 & -3.80 & -4.80 & -13.07 & -1.24 \\
\hline \multicolumn{6}{|l|}{ Major Medical Condition Near End of Life } \\
\hline Cancer & 9.18 & 6.09 & -2.71 & -14.35 & $-26.05^{\S}$ \\
\hline Chronic Obstructive Pulmonary Disease & -4.28 & $-19.09^{\ddagger}$ & -19.98 & -24.50 & $35.59^{\ddagger}$ \\
\hline Diabetes & 11.57 & 3.21 & -3.55 & -12.51 & -12.18 \\
\hline Nephritis & 17.96 & $26.48^{\ddagger}$ & 20.39 & 27.65 & 23.20 \\
\hline Hernia & -5.36 & -10.16 & -21.25 & -19.30 & -4.93 \\
\hline Other Blood Vessel Disorders & 23.54 & 31.02 & 19.24 & 17.68 & -24.18 \\
\hline Constant & $111.39^{\S}$ & $163.69^{\S}$ & $199.53^{\S}$ & $236.87^{\S}$ & $141.13^{\S}$ \\
\hline Pseudo- $R^{2 \uparrow}$ & 0.014 & 0.016 & 0.020 & 0.035 & 0.064 \\
\hline \multicolumn{6}{|l|}{$p$-Value of Joint Test ${ }^{* *}$} \\
\hline Age Indicators & 0.532 & 0.408 & 0.067 & $0.002^{\S}$ & 0.281 \\
\hline Race Indicators & $0.002^{\S}$ & $0.019^{\ddagger}$ & $0.044^{\ddagger}$ & $0.001^{\S}$ & $0.020^{\ddagger}$ \\
\hline Major Medical Conditions Indicators & $0.012^{\ddagger}$ & $<0.001^{\S}$ & $0.001^{\S}$ & $0.003^{\S}$ & $<0.001^{\S}$ \\
\hline $\begin{array}{l}{ }^{*} \text { GLM with family = POISSON and link = POW } \\
{ }^{\dagger} \text { GLM with family = GAMMA and link = POW } \\
{ }^{\ddagger} \text { Statistically significant at } 5 \% \text { level. } \\
{ }^{\S} \text { Statistically significant at } 1 \% \text { level. } \\
{ }^{9} \text { Pseudo- } R^{2}=\text { square of correlation coefficient be } \\
{ }^{* * *} p=\text { probability of rejecting hypothesis that test } \\
\end{array}$ & $\begin{array}{l}0.5 \text { (square root). } \\
0.5 \text { (square root). }\end{array}$ & cted cost. & . & & \\
\hline
\end{tabular}

most of their VA medical care as inpatients when approaching end of life with 98 percent of costs in the final month from inpatient care. VA spent an average of $\$ 61,900$ a person in the year 1 for patients with SCI/D. This amount is double the cost of an average individual without SCI/D paid by Medicare in year 1 [19]. In comparison, the average total VA medical cost in year 1 for veterans in general during the same study period was $\$ 19,200$-less than one-third the cost for those with SCI/D.* Furthermore, while the

*Yu W, Richardson SS, Chow A, Hill A, Garber A. End-of-life care: Medical treatments and costs by age, race, and region. Health Economics Resource Center, VA Palo Alto Health Care System, working paper; 2006 Mar 14. average cost of VA healthcare for a veteran with SCI/D aged 65 to 80 was about $\$ 25,000$ in FY2000, the overall mean for a veteran without SCI/D in the same age group with one or more chronic conditions was about \$5,000 [20]. The difference in costs between veterans with SCI/D and other veterans for both routine and end-of-life costs is large, probably reflecting the complex care veterans with SCI/D often require.

Second, the examination of major medical conditions revealed that the conditions that accounted for the most medical care used near end of life among patients with SCI/D included cancer, heart disease, and influenza and/ or pneumonia. Data from the Model Systems SCI centers indicate that the most common causes of death of veterans were diseases of the respiratory system $(21.9 \%)$ and 
heart diseases (12.4\%) [21]. The two leading causes of death in the United States between 2001 and 2004 were heart disease and cancer. Our results indicate that veterans with SCI/D are dying from the same causes as the general population [22]. What is not clear is why the costs of care at end of life are so much higher for veterans with SCI/D than the costs for the general population. Apparently, veterans with SCI/D are much more likely to die in the hospital and they may have greater other needs due to their impairment (e.g., bowel and bladder care) than the general population. No literature addresses use of hospice in SCI/D, so whether it might offset some of these costs is not known.

The finding that influenza and/or pneumonia was the second most frequent major medical condition for our cohort suggests that preventive care, including respiratory vaccinations, is particularly important for patients with SCI/D. This finding is not surprising, since persons with traumatic SCIs who contract influenza are 37 times more likely to die from respiratory complications than the general population [21]. In the past 5 years, the VA and SCI QUERI have attempted to improve respiratory vaccination rates. Influenza and pneumococcal vaccination rates were only 33 and 50 percent, ${ }^{*}$ respectively, for veterans with SCI/D aged $\geq 65$ when these data were collected; however, in 2006, these rates increased to 72 percent for influenza and 86 percent for pneumonia [23].

Third, healthcare costs for veterans with SCI/D were relatively stable in year 2 and only accelerated in year 1 . In a separate study, we found that the average annual cost, including pharmacy costs, was \$26,735 for all VA patients with SCI/D in FY1999 [14]. Using the Decision Support System data, we found that the average pharmacy cost in year 1 for our study cohort was $\$ 2,100$ for each person. If we assume that pharmacy cost was similar in years 1 and 2 before end of life, the average total cost (including pharmacy costs) for each person in year 2 would be about $\$ 27,000$. Hence, the year- 2 cost was very close to that of all living VA patients with SCI/D. This finding would suggest that persons with SCI/D may have a fairly stable health status until their final 6 to 3 months before end of life when illness, disease, and other complications escalate costs.

\footnotetext{
* Office of Quality and Performance. Performance report. Washington
} (DC): Department of Veterans Affairs; 2000.
Fourth, in multivariate analyses, age was not significantly associated with cost. This pattern is different from that found in the general population. Both Medicare and VA studies have reported that healthcare costs declined with age, including the final month of life $[19,24] .^{\dagger}$ The multivariate analyses also revealed that blacks may not incur significantly higher costs than whites after controlling for demographic, injury, and major medical factors; this also differs from the general population and may warrant additional investigation [19].

This study has several limitations. First, the results of this study may not be generalizable to non-VA persons with SCI/D. Other persons with SCI/D may have different healthcare use patterns during their final months of life. Second, our study may not reflect the disease and cost patterns for women with SCI/D near end of life, because of the small number of women in the cohort. Third, our study only reported VA costs. VA patients may also be eligible for and use other health insurance such as Medicare or Medicaid for additional care. Individuals with SCI/D also may have substantial healthcare costs for attendant and non-VA long-term care. Therefore, we most likely may have underestimated total healthcare costs. Future research to examine use of Medicaid and Medicare services for veterans with SCI/D will allow for more accurate estimates. Fourth, a substantial number of veterans were missing etiology data. Future studies of end-of-life care in this population may require prospective data collection to understand the differences between nontraumatic disorders and traumatic injuries more completely. Finally, our cost estimates did not include outpatient pharmacy data. However, we provided a cost estimate for pharmacy in the discussion as a reference.

\section{CONCLUSIONS}

The costs of caring for veterans with SCI/D near their end of life are substantially higher than what has been reported for VA costs of veterans in the general population. However, end-of-life costs of care for persons with SCI/D escalated only in the final 6 to 3 months before end of life.

\footnotetext{
${ }^{\dagger}$ Yu W, Richardson SS, Chow A, Hill A, Garber A. End-of-life care: Medical treatments and costs by age, race, and region. Health Economics Resource Center, VA Palo Alto Health Care System, working paper; 2006 Mar 14.
} 
Conditions accounting for the greatest costs included cancer, heart disease, and influenza and/or pneumonia. Prevention is important in these areas. Early cancer screening and intervention; receipt of influenza and pneumonia vaccines; and efforts to control blood pressure, cholesterol, and weight in this population should be emphasized.

\section{ACKNOWLEDGMENTS}

Dr. Wei Yu would like to thank Shanghai University of Finance and Economics, China, for the great support in revising and completing this article.

Ms. Shirley Kim is now with Reden \& Anders, San Francisco, California and Dr. Yu is with Shanghai University, Shanghai, China.

This material was based on work supported by U.S. VA Health Services Research and Development Service grant IIR-02-189.

The views expressed in this article are those of the authors and do not reflect those of VA, Shanghai University of Finance and Economics, or Northwestern University.

The authors have declared that no competing interests exist.

\section{REFERENCES}

1. DeVivo MJ, Fine PR, Maetz HM, Stover SL. Prevalence of spinal cord injury: a reestimation employing life table techniques. Arch Neurol. 1980:37(11):707-8. [PMID: 7436813]

2. Lasfargues JE, Custis D, Morrone F, Carswell J, Nguyen T. A model for estimating spinal cord injury prevalence in the United States. Paraplegia. 1995;33(2):62-68.

[PMID: 7753569$]$

3. Glick T. SCI surveillance: Is there a decrease in incidence? [abstract]. J Spinal Cord Med. 2000;23 Suppl:61.

4. DeVivo MJ, Whitneck GG, Charles ED Jr. The economic impact of spinal cord injury. In: Stover SL, DeLisa JA, Whiteneck GG, editors. Spinal cord injury: clinical outcomes from the model systems. Gaithersburg (MD): Aspen Publications; 1995. p. 234-71.

5. DeVivo MJ. Causes and costs of spinal cord injury in the United States. Spinal Cord. 1997;35(12):809-13. [PMID: 9429259]

6. Spinal Cord Injury Information Network [Internet]. Birmingham (AL): National Spinal Cord Injury Statistical Center; (C) 1998-2003. Facts \& stats: Spinal cord injuries facts and fig- ures at a glance; 2006 Jun [cited 2006 Dec 19]; [about 3 screens]. Available from: http://www.spinalcord.uab.edu/.

7. McKinley WO, Seel RT, Hardman JT. Nontraumatic spinal cord injury: incidence, epidemiology, and functional outcome. Arch Phys Med Rehabil. 1999;80(6):619-23. [PMID: 10378485]

8. Guttman L. Spinal cord injuries: Comprehensive management and research. Oxford (England): Blackwell Scientific; 1976.

9. Murray PK, Kusier MF. Epidemiology of nontraumatic and traumatic spinal cord injury [abstract]. Arch Phys Med Rehabil. 1994;65:634.

10. Middleton JW, Lim K, Taylor L, Soden R, Rutkowski S. Patterns of morbidity and rehospitalisation following spinal cord injury. Spinal Cord. 2004;42(6):359-67. [PMID: 15007376]

11. Ditunno JF Jr, Formal CS. Chronic spinal cord injury. N Engl J Med. 1994;330(8):550-56. [PMID: 8302323]

12. Wagner TH, Chen S, Barnett PG. Using average cost methods to estimate encounter-level costs for medical-surgical stays in the VA. Med Care Res Rev. 2003;60(3 Suppl):15S-36S. [PMID: 15095543]

13. Phibbs CS, Bhandari A, Yu W, Barnett PG. Estimating the costs of VA ambulatory care. Med Care Res Rev. 2003; 60(3 Suppl):54S-73S. [PMID: 15095546]

14. Yu W, Ravelo A, Wagner TH, Phibbs CS, Bhandari A, Chen S, Barnett PG. Prevalence and costs of chronic conditions in the VA health care system. Med Care Res Rev. 2003;60(3 Suppl):146S-67S. [PMID: 15095551]

15. Kochanek KD, Murphy SL, Anderson RN, Scott C. Deaths: Final data for 2002. Natl Vital Stat Rep. 2004; 53(5):1-116.

16. McCullagh P, Nelder JA. Generalized linear models. 2nd ed. London (England): Chapman and Hall; 1989.

17. Manning WG, Mullahy J. Estimating log models: to transform or not to transform? J Health Econ. 2001;20(4):461-94. [PMID: 11469231]

18. Mullahy J. Much ado about two: reconsidering retransformation and the two-part model in health econometrics. J Health Econ. 1998;17(3):247-81. [PMID: 10180918$]$

19. Levinsky, NG, Yu W, Ash A, Moskowitz M, Gazelle G, Saynina O, Emanuel EJ. Influence of age on Medicare expenditures and medical care in the last year of life. JAMA. 2001;286(11):1349-55. [PMID: 11560540]

20. Yu W, Ravelo A, Wagner TH, Barnett PG. The relationships among age, chronic conditions, and healthcare costs. Am J Manag Care. 2004;10(12):909-16. [PMID: 15617366]

21. DeVivo MJ, Black KJ, Stover SL. Causes of death during the first 12 years after spinal cord injury. Arch Phys Med Rehabil. 1993;74(3):248-54. [PMID: 8439250]

22. Centers for Disease Control and Prevention. QuickStats: Age adjusted death rates for the five leading causes of deathUnited States, 2001-2004. MMWR Morb Mortal Wkly Rep. 2006;55(39):1075. 
23. Office of Quality and Performance [Internet]. Performance Report Executive Summary. Washington (DC): Department of Veterans Affairs. End of Year VISN Summary ReportFY2005; [cited 2006 Jul 11]; [about 1 screen]. Available from: http://vaww.oqp.med.va.gov/Publications/EBB/SummaryReports/8)\%20VISN\%20Summary\%20Spotlight\%2005.xls/.
24. Hogan C, Lunney J, Gabel J, Lynn J. Medicare beneficiaries’ costs of care in the last year of life. Health Aff (Millwood). 2001;20(4):188-95. [PMID: 11463076]

Submitted for publication August 26, 2006. Accepted in revised form January 14, 2008. 
